BULLETIN Bulletin hispanique

HISPANIQUE Université Michel de Montaigne Bordeaux

119-2 | 2017

La Égloga renacentista en el Reino de Nápoles

\title{
Ana Ma. Freire López y Dolores Thion Soriano- Mollá (estudio preliminar y edición), Cartas de buena amistad. Epistolario de Emilia Pardo Bazán a Blanca de los Ríos (1893-1919)
}

Iberoamericana/Vervuert, Madrid/Frankfurt, 2016

Jean-François Botrel

\section{OpenEdition}

Journals

\section{Édition électronique}

URL : http://journals.openedition.org/bulletinhispanique/5247

DOI : 10.4000/bulletinhispanique.5247

ISSN : 1775-3821

Éditeur

Presses universitaires de Bordeaux

\section{Édition imprimée}

Date de publication : 1 décembre 2017

Pagination : 792-794

ISBN : 979-10-300-0218-8

ISSN : 0007-4640

Référence électronique

Jean-François Botrel, « Ana Ma. Freire López y Dolores Thion Soriano-Mollá (estudio preliminar y edición), Cartas de buena amistad. Epistolario de Emilia Pardo Bazán a Blanca de los Ríos (1893-1919) », Bulletin hispanique [En ligne], 119-2 | 2017, mis en ligne le 28 novembre 2017, consulté le 16 janvier 2021. URL : http://journals.openedition.org/bulletinhispanique/5247 ; DOI : https://doi.org/10.4000/ bulletinhispanique.5247

Ce document a été généré automatiquement le 16 janvier 2021.

Tous droits réservés 


\section{Ana Ma. Freire López y Dolores Thion Soriano-Mollá (estudio preliminar y edición), Cartas de buena amistad. Epistolario de Emilia Pardo Bazán a Blanca de los Ríos (1893-1919)}

Iberoamericana/Vervuert, Madrid/Frankfurt, 2016

Jean-François Botrel

\section{RÉFÉRENCE}

Ana Ma. Freire López y Dolores Thion Soriano-Mollá (estudio preliminar y edición), Cartas de buena amistad. Epistolario de Emilia Pardo Bazán a Blanca de los Ríos (1893-1919), Madrid/Frankfurt, Iberoamericana/Vervuert, 2016, 219 pages.

1 En raison de leur évident intérêt biographique et documentaire, on sait que, pour les écrivains, les correspondances épistolaires sont comme les antécédents et les dessous de l'œuvre littéraire ou journalistique, susceptibles d'expliquer ou de clarifier les opacités de l'œuvre. C'est pourquoi on a justement tendance à les considérer comme partie intégrante de l'œuvre d'un écrivain, comme une œuvre épistolaire à la fois constitutive et éclairante de l'œuvre complète.

2 Pour le Grand Réalisme espagnol, on a déjà pu apprécier ce que représente l'apport des lettres de ou à Galdós ou Leopoldo Alas «Clarín» ou celles de Valera, par exemple. S'agissant d'Emilia Pardo Bazán, on connaissait ses lettres à Giner, à Menéndez Pelayo, à Galdós (sans doute les plus connues et lues), ou à Ferrari (en attendant celles à Clarín dont Jesús Rubio prépare l'édition), mais ces 39 lettres et 45 cartes de visite ou billets 
adressés par elle à Blanca de los Ríos de Lampérez entre 1893 et 1919 ont cet intérêt particulier qu'il s'agit d'une correspondance entre deux femmes écrivaines qui se revendiquent comme intellectuelles («los intelectuales somos propensos a los ataques del toedium vitce ", assure Pardo Bazán) tout en assumant, avec compétence et naturel, sans rechigner, «las labores propias de su sexo », comme on disait alors, soit le rôle d'épouse ou de mère que la société de l'époque leur attribuait avant tout. Quelque chose de lucidement jugé par Emilia Pardo Bazán lorsqu'elle confie à sa correspondante : « Me ha hecho reír lo que dice usted de las damas españolas. A mí no me dio nunca por emancipar a la mujer; pero le digo a usted que si me diese, estaba fresca. Es inconcebible cómo viven en general las señoras; pero sus maridos están contentos, la sociedad también, todo el mundo lo halla bueno, ergo debe seguir así».

3 Dans cette correspondance on trouvera donc des confidences de Pardo Bazán sur le métier d'écrivain (à propos des contes et articles qui, à son avis, ne sont que «perdigones ; las balas no salen ») ou sur des projets en matière de théâtre (une obsession également présente chez Blanca de los Ríos et la plupart des écrivains de l'époque) aussi bien que des considérations sur la difficile éducation des domestiques, sur la préparation du mariage de sa fille Blanca, ou encore sur les travaux engagés, à partir de 1894, au Pazo de Meiras, pour transformer la "granja rústica» initiale en un pazo qui devait, en 1938, être offert à Franco. Emilia Pardo Bazán se plaint d'ailleurs de cette condition féminine : "la marcha de la casa, los ahogos de la prosa, la brega con los criados, cansan tanto o más que el esfuerzo intelectual, cuando es gustosa la labor literaria ", écrit-elle le 7 septembre 1906.

4 Comme la plupart des lettres reçues par Emilia Pardo Bazán et conservées au Pazo de Meiras semblent avoir été détruites du temps du nouvel occupant, il manque à cette correspondance la voix de Blanca de los Ríos de Lampérez, mais la parfaite connaissance qu'ont A.-M. Freire et D. Thion-Soriano des parcours des deux correspondantes leur permet, sans difficulté apparente, de reconstituer leurs échanges en comblant presque tous les silences ou les blancs. C'est ce à quoi contribue l'étude préliminaire (pp. 7-68) où sont apportées toutes les informations nécessaires sur le contexte vital de cette amitié entre une écrivaine déjà bien installée dans le champ littéraire et une apprentie qui n'en est qu'au début d'une longue carrière (B. de los Ríos mourra en 1956), sur le contenu, le ton et le style des lettres, la création littéraire de Blanca de los Ríos, l'évolution de la production romanesque de Pardo Bazán, les aspirations des deux femmes à conquérir la scène, la candidature d'Emilia Pardo Bazán à la présidence de l'Ateneo en 1905 et la construction du pazo de Meirás. À cela s'ajoute un très efficace et exhaustif système de notes qui fait qu'on puisse lire les lettres manquantes "entre líneas y como reflejadas en un espejo ", comme l'écrivent les éditrices (p. 68).

5 Dans ce dialogue reconstitué, on devine aisément que la voix qui prédomine est, pour tous les domaines de la vie, celle du mentor qu'est pour sa cadette de onze ans, Emilia Pardo Bazán : en maîtresse-femme, elle lui prodigue aussi bien des conseils sur la façon de soigner ses « alifafes » et « dolamas » en Suisse ou en Galice (à la Toja ou à Mondariz) que sur les orientations de sa carrière littéraire. Elle ne craint pas non plus, si besoin est, de la transformer en sa «muñidora electoral », comme lors de sa candidature à la présidence de l'Ateneo présentée, malgré l'échec, comme un « triunfo de la mujer ».

6 Mais le lecteur sera certainement aussi sensible au plaisir que procurent les « genialidades epistolares y verbales » ainsi qualifiées par «doña Emilia » elle-même, dans 
sa lettre du 31 mai 1905, son inimitable faconde et sa familiarité ou désinvolture qui l'amènent, par exemple, pour vanter son "exceptionnelle résistance", à se comparer au Cid (" ¿Miedo yo ? El Cid, a mi lado, un chipilín de teta »), à écrire que « ni con microscopio, veo la utilidad (para nosotros) de inscribirnos en esa asociación» (une association française non identifiée) ou, le 3 octobre 1902, à expédier une oraison funèbre de Zola, mort le 29 septembre dans les circonstances que l'on sait, en ces termes: " La muerte de Zola ha sido más bien insípida. ¡Mire $V$. que calentarse con carbón mineral, la cosa más dañosa, un escritor abogado del progreso, de la higiene, un naturalista! Yo que solo al acercarme a una chimenea de carbón me pongo trastornada de jaqueca! ¡Dormir así! Vamos, es asombrosa la inconsecuencia humana».

7 Dans cette minutieuse édition critique, parfaitement mise en livre par IberoamericanaVervuert, il est, par ailleurs, justement rendu compte de la matérialité des missives (dont une seule est écrite à la machine, en 1913, parce que Pardo Bazán se dit «mareada ») et l'environnement de cette correspondance se trouve habilement évoqué par la reproduction de nombreux documents, dont, p. 59, une photographie de Blanca de los Ríos d'avant 1907 et deux ou trois échantillons de l'écriture de Pardo Bazán.

8 En 1916, Emilia Pardo Bazán écrivait à Miguel de Unamuno : «Es usted un Sévigné. Lo mejor de cuanto usted hace es lo epistolar. Y no crea que esto es un grano de anís. Ya van quedando pocas gentes que sepan tornear (sin proponérselo, sin afectación) las cartas y los billetes ».

9 Après la lecture de ces Cartas de buena amistad, on peut sans conteste lui retourner le compliment.

\section{AUTEURS}

\section{JEAN-FRANÇOIS BOTREL}

Université Rennes 2 